\title{
openheart Empowering podiatrists to perform pulse checks for opportunistic atrial fibrillation detection during annual diabetes foot checks
}

\author{
Linda Hicks, ${ }^{1}$ Julia Newton, ${ }^{2}$ Rahul Nayar, ${ }^{3}$ Kate Mackay ${ }^{2}$
}

To cite: Hicks L, Newton J, Nayar R, et al. Empowering podiatrists to perform pulse checks for opportunistic atrial fibrillation detection during annual diabetes foot checks. Open Heart 2019;6:e000795. doi:10.1136/

openhrt-2018-000795

Received 5 February 2018 Revised 24 October 2018 Accepted 20 December 2018

A Check for updates

\section{(C) Author(s) (or their} employer(s)) 2019. Re-use permitted under CC BY-NC. No commercial re-use. See rights and permissions. Published by BMJ.

${ }^{1}$ Podiatry Department, County Durham and Darlington NHS Foundation Trust, Durham, UK ${ }^{2}$ Academic Health Science Network North East and North Cumbria (AHSN), Biomedical Research Building, Campus for Ageing and Vitality, Newcastle, UK

${ }^{3}$ Northern Diabetes Footcare Network, Northern England Clinical Networks, NHSE and City Hospitals, Sunderland, UK

Correspondence to Dr Julia Newton; julia.newton@ ncl.ac.uk

\section{ABSTRACT}

Objective To determine whether training podiatrists to provide opportunistic screening for atrial fibrillation (AF) during the local diabetes foot check was feasible and whether it detects previously unknown AF.

Method During the initiative, 45 podiatrists from across North Durham, Darlington and Durham Dales Easington and Sedgefield Clinical Commissioning Groups were trained to recognise heart irregularities when taking pulse readings of feet of patients with diabetes during their annual foot screening reviews.

Results Over the course of the 3-month pilot, 5000 patients with diabetes had their feet pulse-tested. The project uncovered that for every 500 patients who had their feet checked, one new case of AF could be identified. Conclusion A report following the Podiatry and Atrial Fibrillation Case Finding scheme revealed that the National Health Service in the United Kingdom North East and North Cumbria area could benefit from potential cost savings in excess of $£ 500000$. In 2013, the National Diabetes Information Service, Yorkshire and Humber Public Health Observatory estimated 231777 people in the North East, North Cumbria, Hambleton and Richmondshire area with diabetes. Therefore 463 patients could be found with AF, preventing 23 strokes and saving $£ 539742$ or in excess of $£ 0.5 \mathrm{M}$.

\section{INTRODUCTION}

Atrial fibrillation (AF) is a common heart condition causing an irregular heart rate. ${ }^{1}$ It affects around 1 million people in England with a further 425000 estimated to be living with undiagnosed $\mathrm{AF}^{2}$ In those aged over 65, almost 1 in 10 people are affected by AF which is often asymptomatic. ${ }^{3}$ Without treatment, those living with $\mathrm{AF}$ are five times more likely to suffer a stroke ${ }^{4}$ costing the United Kingdom National Health Service (NHS) on average £23 315 per patient. $^{5}$

In the UK, stroke affects one person every $5 \mathrm{~min}$. It is a leading cause of adult disability. ${ }^{67}$ Strokes related to AF are considered to be more severe and cause greater disability than strokes in those without $\mathrm{AF}^{89}$

\section{Key questions}

What is already known about this subject?

- Atrial fibrillation (AF) is a common heart condition that affects around 1 million people in England with a further 425000 estimated to be living with undiagnosed AF.

- Without treatment, those living with AF are five times more likely to suffer a stroke costing the National Health Service (NHS) on average £23 315 per patient.

- Estimates suggest around half of patients with AF remain undetected.

- Training for podiatrists to provide opportunistic screening for AF during a local diabetes foot check represents an opportunity to detect previously unknown AF.

What does this study add?

- Diabetic foot checks represent a feasible opportunity to screen for unknown AF.

- Our study suggests that for every 500 patients with diabetes having their feet checked, one new case of AF would be identified.

- Using data from the Stroke Association, this would prevent two strokes per year, which equates to a cost-saving of $£ 46630$.

How might this impact on clinical practice?

- Our pilot study has highlighted the potential for opportunistic screening for AF by trained podiatrists during a diabetic foot check.

- Podiatry staff were assessing pulse presence using Doppler and with training were also able to listen for pulse rhythm. This would appear to be a significant screening opportunity to ensure those with irregular pulses are identified.

- Across England, if all patients with diabetes had their pulse checked as part of the annual review screening for an irregular pulse, we believe that approximately 7600 people could be detected with AF. If 7600 patients were correctly anticoagulated, 380 strokes could be prevented saving the NHS approximately £8.8 million (minus the cost of treatment).

Following a stroke, half of all patients with AF will die within 12 months. ${ }^{8}$ For those who survive, living with the consequences of a 
stroke can be worse than dying, as disability and fear of death become significant issues. ${ }^{10}$ In addition to devastating patients' lives, AF and stroke also impact on the lives of their families and carers. ${ }^{11}$

Despite the availability of free and simple checks, estimates suggest around half of patients with AF remain undetected. ${ }^{12}$ This is frequently because people are unaware that the symptoms they experience are a sign of anything serious. ${ }^{12} 13$ For many, experiencing a stroke is the first sign of underlying AF. ${ }^{14}$

As the population ages, the current situation is predicted to worsen as the number of people with $\mathrm{AF}$ is expected to more than double by $2050 .{ }^{15} 16$ Therefore, our ageing population will increase both the number of people with $\mathrm{AF}$ and the number of strokes that result from $\mathrm{AF} .{ }^{17}$ Furthermore, this increase will be amplified as we become better at preventing deaths from other conditions, such as heart attacks, which themselves increase the risk of $\mathrm{AF}^{18}$

When used correctly, existing treatments are effective and could prevent AF-related strokes, saving thousands of lives and millions of pounds from the NHS budget. For example, when anticlotting therapy is used appropriately, it is highly effective, lowering stroke risk by approximately two-thirds in patients with $\mathrm{AF}^{19}$

There is therefore an urgent need for coordinated action within healthcare systems including the NHS to achieve earlier diagnosis and better management to reduce the risk of stroke in patients with AF. One approach recommended by national and international bodies is the use of targeted screening programmes drawing on routine manual pulse checks and ECG readings.

Diabetes is a common condition affecting 3.8 million people across England. ${ }^{20}$ In order to prevent diabetes complications, it is recommended that those with diabetes have their pulse checked as part of an annual foot check review with recommendations that all patients aged 12 and over should be offered a foot check aimed at identifying early peripheral vascular disease. Despite this recommendation, unlike for diabetic eye checks, there is currently no national screening programme for either pulse checking or diabetes foot screening. As a result, local policies regarding the delivery of diabetic foot checks are variable and aimed primarily at detecting whether pulses are present rather than determine its rhythm. Currently, any person detected with an irregular pulse, through whatever means, is usually referred from their primary care clinicians (general practitioner, GP) for a 12-lead ECG to confirm diagnosis. Arrangements for diabetes foot checks are made locally and vary between clinical commissioning group (CCG) areas.

In the current study, we implemented training for podiatrists in order to determine whether an opportunistic screening for AF during the local diabetes foot check was feasible and whether it detects previously unknown $\mathrm{AF}$.

\section{METHOD}

Durham and Darlington Podiatry Services serve a large area of 622000 people living in a diverse geographical area of both urban and rural communities across North Durham CCG, Darlington CCG and Durham Dales Easington and Sedgefield (DDES) CCG. After discovering a patient with an irregular pulse, the Service undertook this pilot project to examine the number of people with previously unknown AF detected in the diabetes foot check. This enhanced service was delivered for 3 months, from 1 January 2016 to 31 March 2016. The team of 45 podiatrists and footcare technicians were assessing pulse presence and flow using a Doppler system. They were trained to listen for both pulse rhythm as well as presence prior to the project starting and continue to have updates. Any patients detected with an irregular pulse using the standard Doppler assessment, who did not already have a diagnosis of AF, were referred to their primary care physician (GP) for a 12-lead ECG to confirm or rule out AF. After 30 June 2016, those individuals referred back to the GP had their final diagnosis checked via their electronic patient record in order to discover whether the detected irregular pulse was subsequently diagnosed as AF. Staff had their notes audited which encouraged records to be completed.

\section{RESULTS}

A total of 5000 patients had their feet checked using pulse Doppler within the 3-month period, and 10 patients were identified with previously unknown AF. Therefore, for every 500 patients with diabetes having their feet checked, one new case of AF was identified.

Extrapolating figures from 3 months to 12 months suggests that 40 new patients with AF could be identified annually across North Durham, Darlington and DDES CCGs by encouraging appropriately trained podiatrists to consider AF when performing a pulse check as part of the diabetes foot check. Using data from the Stroke Association, ${ }^{4}$ this would prevent two strokes per year, which equates to a cost-saving of $£ 46630 .^{5}$

In 2013, the National Diabetes Information Service, Yorkshire and Humber Public Health Observatory estimated 231777 people in the North East, North Cumbria, Hambleton and Richmondshire area with diabetes. ${ }^{1}$ Therefore, 463 people could be found with $\mathrm{AF}$, preventing 23 strokes and saving £539 742 or in excess of $£ 0.5$ million.

\section{CONCLUSION}

Our pilot study has highlighted the potential for opportunistic screening for AF by trained podiatrists during the diabetic foot check. Podiatry staff were already assessing whether a foot pulse is present, and by training them to also consider whether the pulse is regular would appear to be a significant screening opportunity to ensure those with irregular pulses are identified. As a professional 
group, podiatrists are ideally placed to provide this opportunistic screening and were very receptive to the programme and recognised their clinical responsibility to help detect AF. By raising staff awareness of AF and empowering them, the podiatrists felt they could have an impact on a patient's life, possibly even saving a life.

The pilot has been an excellent opportunity to raise awareness of the condition among healthcare professionals and training continues to be rolled out through County Durham and Darlington and the Northern Diabetes Footcare Network.

Across England, if all patients with diabetes had their pulse checked as part of the annual review screening for an irregular pulse, we anticipate that approximately 7600 people could be detected with AF. If 7600 patients were correctly anticoagulated, 380 strokes could be prevented saving the NHS approximately $£ 8.8$ million (minus the cost of treatment).

Contributors All authors contributed to the design of the study and reviewed and approved the final draft. LH performed the training and collated the data. KM and RN had the original idea and wrote the first draft. JN performed the analysis.

Funding The project was funded by the Academic Health Science Network NENC.

Competing interests None declared.

Patient consent for publication Not required.

Provenance and peer review Not commissioned; externally peer reviewed.

Data sharing statement No additional data are available.

Open access This is an open access article distributed in accordance with the Creative Commons Attribution Non Commercial (CC BY-NC 4.0) license, which permits others to distribute, remix, adapt, build upon this work non-commercially, and license their derivative works on different terms, provided the original work is properly cited, appropriate credit is given, any changes made indicated, and the use is non-commercial. See: http://creativecommons.org/licenses/by-nc/4.0/.

\section{REFERENCES}

1. NDIS, YHPHO, 2013. Levels of diabetes in the North East, North Cumbria, Hambleton and Richmondshire area. Available: [Accessed www.yhpho.org.uk/resource/view.aspx?RID=189815]

2. Public Health England (PHE). Atrial fibrillation prevalence estimates in England: application of recent population estimates. AF: Sweden, August, 2017.

3. National Institute for Health and Care Excellence (NICE). Atrial fibrillation management: CG180, August, 2014.
4. The Stroke Association. State of the nation: stroke statistics, January, 2017.

5. National Audit Office. Progress in improving stroke care, report on the findings from our modelling of stroke care provision (February 2010). NAO Report, 2009-2010.

6. Adamson J, Beswick A, Ebrahim S. Stroke and disability in Journal of Stroke and Cerebrovascular Diseases, 2004: 4.

7. National Audit Office Report. Reducing brain damage: faster access to better stroke care. Department of Health, 2005.

8. Marini C, De Santis F, Sacco S, et al. Contribution of atrial fibrillation to incidence and outcome of ischemic stroke: results from a population-based study. Stroke 2005;36:1115-9.

9. Lamassa M, Di Carlo A, Pracucci G, et al. Characteristics, outcome, and care of stroke associated with atrial fibrillation in Europe: data from a multicenter multinational hospital-based registry (the European Community Stroke Project). Stroke 2001;32:392-8.

10. Wolfe CD. The impact of stroke. Br Med Bull 2000;56:275-86.

11. White CL, Poissant L, Coté-LeBlanc G, et al. Long-term caregiving after stroke: the impact on caregivers' quality of life. J Neurosci Nurs 2006;38:354-60.

12. Kirchhof $P$, Auricchio $A, B a x ~ J$, et al. Outcome parameters for trials in atrial fibrillation: recommendations from a consensus Conference organized by the German Atrial Fibrillation Competence Network and the European Heart Rhythm Association. Europace 2007;9:1006-23.

13. Fuster V, Rydén LE, Cannom DS, et al. ACC/AHA/ESC 2006 guidelines for the management of patients with atrial fibrillation: a report of the American College of Cardiology/American Heart Association Task Force on practice guidelines and the European Society of Cardiology Committee for practice guidelines (writing Committee to revise the 2001 guidelines for the management of patients with atrial fibrillation): developed in collaboration with the European Heart Rhythm Association and the Heart Rhythm Society. Circulation 2006;114:e257-354.

14. Lip GY, Kamath S, Jafri M, et al. Ethnic differences in patient perceptions of atrial fibrillation and anticoagulation therapy: the West Birmingham Atrial Fibrillation Project. Stroke 2002;33:238-42.

15. Go AS, Hylek EM, Phillips KA, et al. Prevalence of diagnosed atrial fibrillation in adults: national implications for rhythm management and stroke prevention: the anticoagulation and risk factors in atrial fibrillation (atria) study. JAMA 2001;285:2370-5.

16. Miyasaka Y, Barnes ME, Gersh BJ, et al. Secular trends in incidence of atrial fibrillation in olmsted county, Minnesota, 1980 to 2000, and implications on the projections for future prevalence. Circulation 2006;114:119-25.

17. Gage BF, Waterman AD, Shannon W, et al. Validation of clinical classification schemes for predicting stroke: results from the National Registry of atrial fibrillation. JAMA 2001;285:2864-70.

18. Briffa $\mathrm{T}$, Hickling $\mathrm{S}$, Knuiman $\mathrm{M}$, et al. Long term survival after evidence based treatment of acute myocardial infarction and revascularisation: follow-up of population based Perth MONICA cohort, 1984-2005. BMJ 2009;338:b36.

19. Lip GY, Lim HS. Atrial fibrillation and stroke prevention. Lancet Neurol 2007;6:981-93.

20. National Cardiovascular Intelligence Network (NCVIN), PHE. Press release, 3.8 million people in England now have diabetes, 13th September, 2016. 